Supporting Information for: Relating Structure and Ice Nucleation of Mixed Surfactant Systems Relevant to Sea Spray Aerosol

Russell J. Perkins, ${ }^{1 *}$ Maria G. Vazquez de Vasquez, ${ }^{2}$ Emma E. Beasley, ${ }^{2}$ Thomas C. J. Hill, ${ }^{1}$ Elizabeth A. Stone, ${ }^{3}$ Heather C. Allen, ${ }^{2}$ Paul J. DeMott ${ }^{1}$

1. Department of Atmospheric Science, Colorado State University, Fort Collins, Colorado 80523, United States

2. Department of Chemistry and Biochemistry, The Ohio State University, Columbus, Ohio 43210, United States

3. Department of Chemistry, University of lowa, lowa City, lowa 52242, United States

\title{
*rperkins@ colostate.edu
}

\begin{tabular}{|l|r|}
\hline Contents: & Page: (S1-S12) \\
\hline Cover Sheet and Contents & S1 \\
\hline Supporting Methods & S2 \\
\hline Figure S1: Fatty Alcohol Mass & S4 \\
\hline Figure S2: Surface Pressure and Surface Potential Isotherms & S5 \\
\hline Figure S3: IRRAS Spectra & S6 \\
\hline Figure S4: Additional BAM Images & S7 \\
\hline Table S1: Film Phase MMA ranges & S9 \\
\hline Figure S5: $10 \mu \mathrm{m}$ Aerosol Growth Curves & S10 \\
\hline Figure S6: 0.1 $\mu \mathrm{m}$ Aerosol Growth Curves & S11 \\
\hline Figure S7: Sample Freezing Curves & S12 \\
\hline References & . \\
\hline
\end{tabular}




\section{Supporting Methods:}

Infrared reflection-absorption spectroscopy (IRRAS) is a surface-sensitive technique and has commonly been used to obtain structural information of surfactants at the air-water interface. A custom-built IRRAS set up was utilized in the chamber of a Fourier transform infrared (FT-IR) spectrometer (Frontier, Perkin-Elmer), with a liquid nitrogen cooled MCT detector. During the experiments a Langmuir trough was placed inside the FT-IR spectrometer. Two gold mirrors were used to reflect the IR beam off the surface of the water contained in the trough. The mirrors were fixed at an incidence angle for $48^{\circ}$ from the surface normal. Each spectrum was collected as an average of 400 scans using an unpolarized light single beam mode over the full spectral range of $4000-450 \mathrm{~cm}^{-1}$ at a $4 \mathrm{~cm}^{-1}$ resolution. IRRAS spectra were plotted as reflectanceabsorbance (RA). The RA is calculated as $-\log \left(R_{m} / R_{0}\right)$ where $R_{m}$ is the reflectivity of the monolayer and $R_{0}$ is the reflectivity of the subphase, in this case nanopure DI water. Data analysis was performed by using Origin software (OriginLab 9, Northampton, MA USA). The spectra shown here are plotted as an average of at least three individual spectra using the average function on Origin which has been baseline-subtracted by a $4^{\text {th }}$ order polynomial. In order to compare the spectra of the both the pure solutions and the mixture an additional scaling factor is required to account for the surface density of the films. To calculate this, the ratio of the MMA of the film in question to the fatty alcohol film was calculated. In this case all films were held at $40 \mathrm{mN} / \mathrm{m}$, so the MMA used could be taken from the compression isotherms shown in Figure 7. 


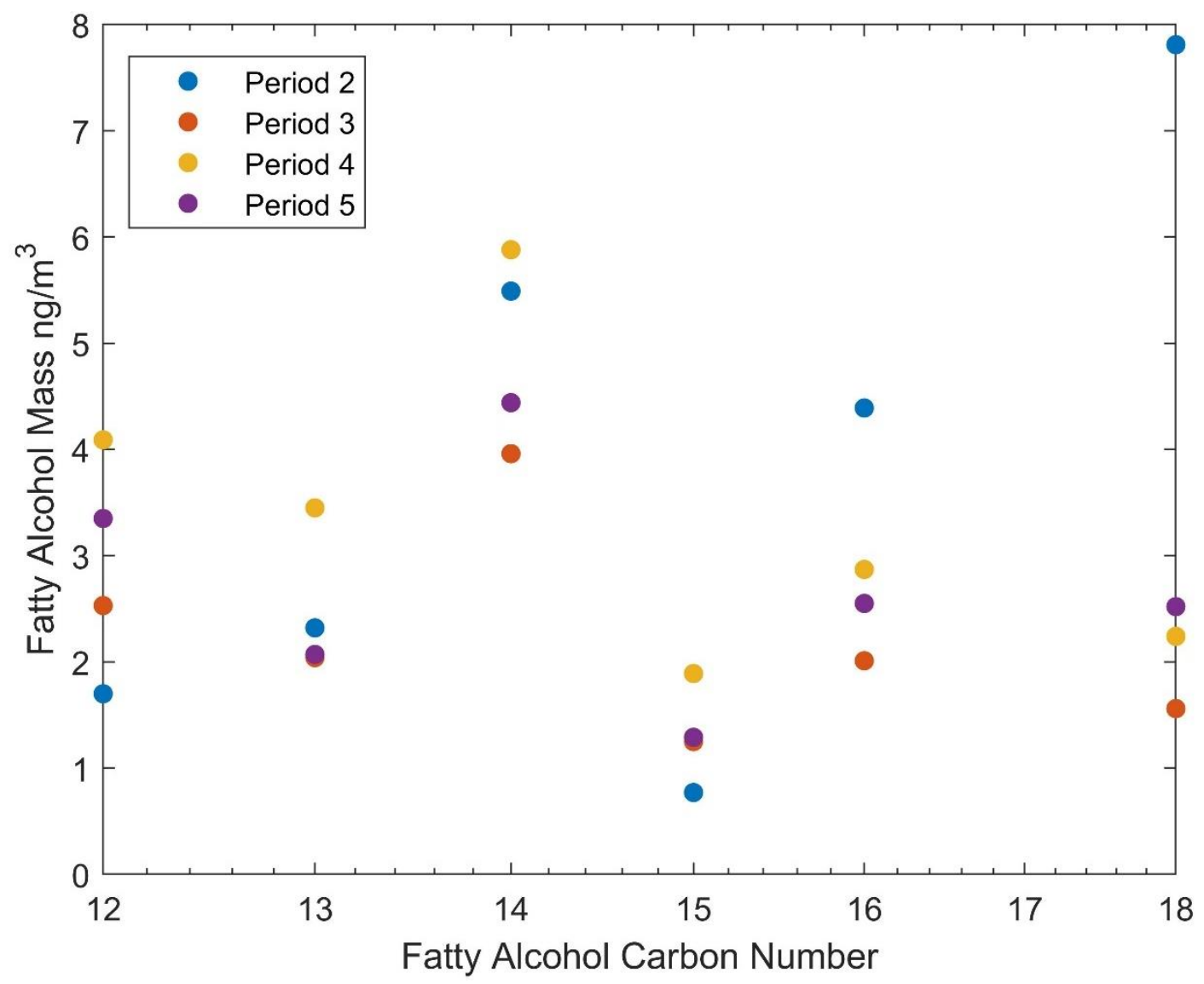

Figure S1: Total mass of each measured fatty alcohol from collected aerosol, summed across all size fractions. Different measurement periods are described in Cochran et al. ${ }^{1}$ 

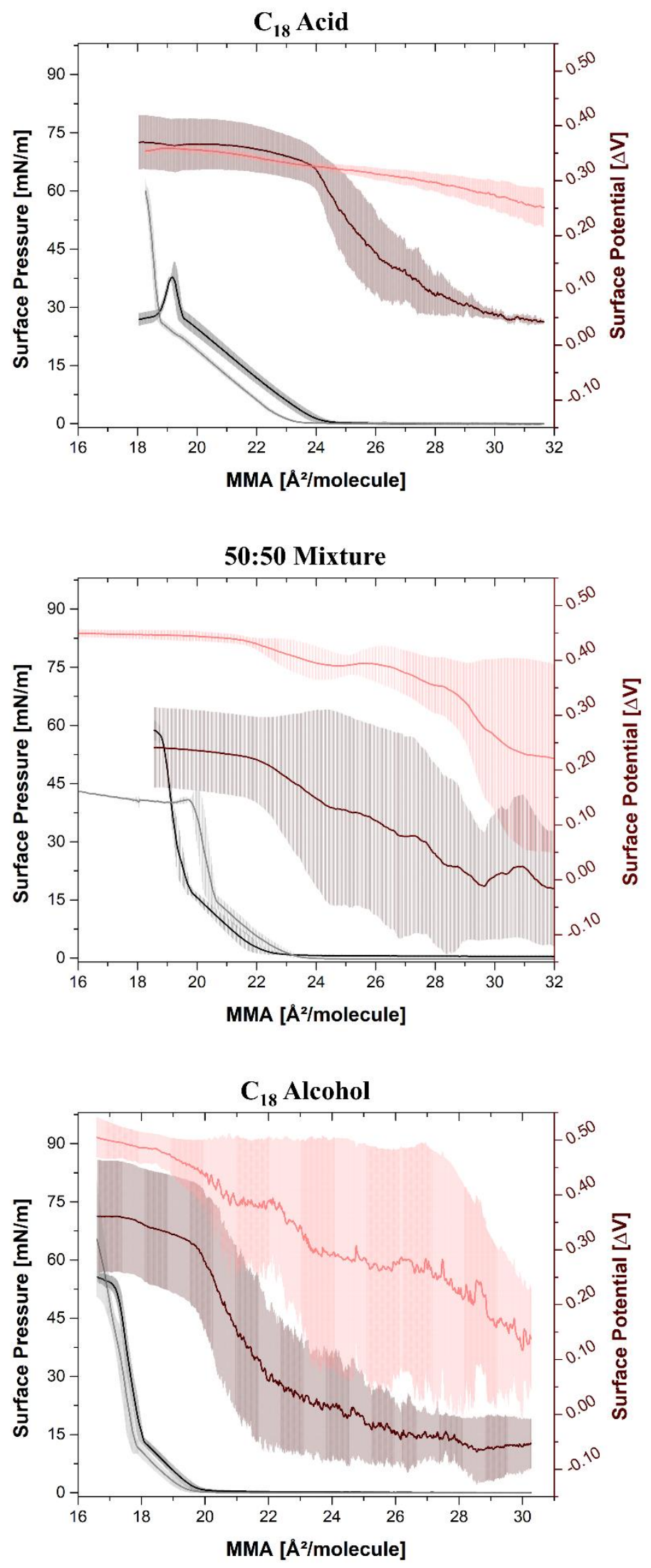

Figure S2: Surface pressure and surface potential during compression isotherms at 24 and $2{ }^{\circ} \mathrm{C}$. Surface potentials are shown in maroon (24 $\left.{ }^{\circ} \mathrm{C}\right)$ and pink $\left(2{ }^{\circ} \mathrm{C}\right)$. Surface pressures are shown in black $\left(24^{\circ} \mathrm{C}\right)$ and grey $\left(2{ }^{\circ} \mathrm{C}\right)$. Shaded regions show standard deviation of three trials. Films were composed of pure $\mathrm{C}_{18}$ fatty alcohol film (top), pure $\mathrm{C}_{18}$ fatty acid film (bottom), and 50:50 mixture of the two (middle). 

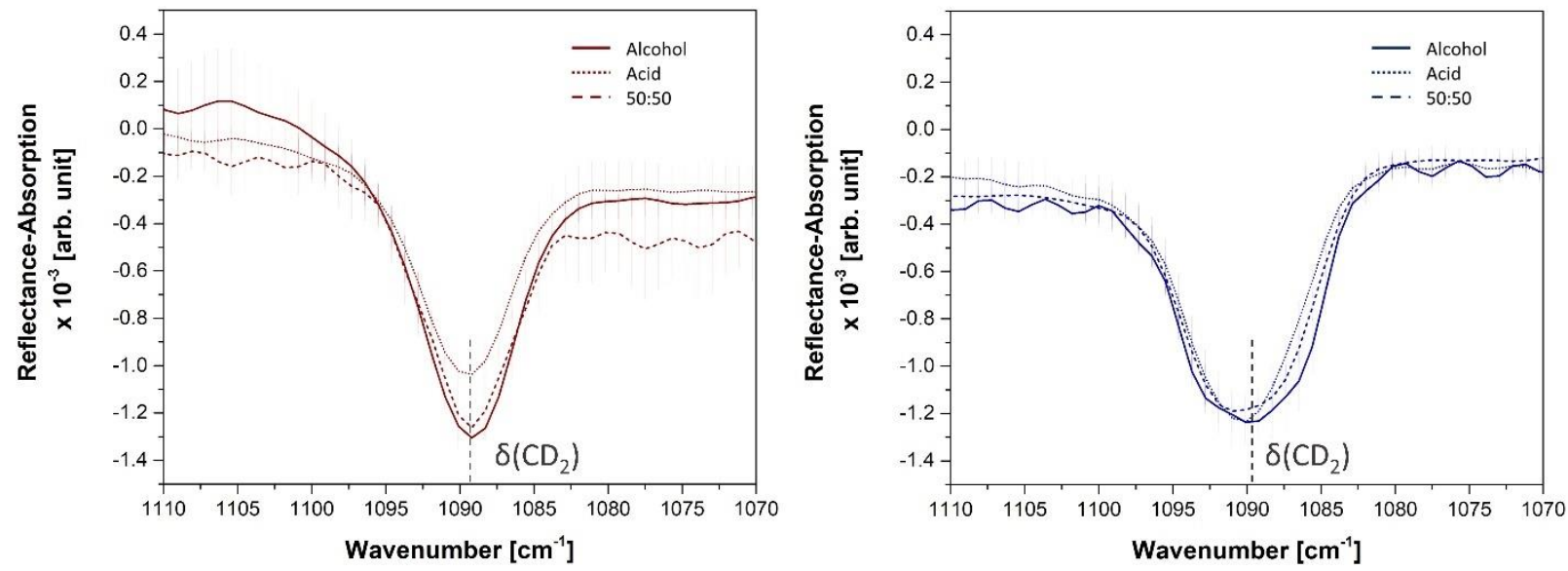

Figure S3: Vibrational modes associated with the $\mathrm{CD}_{2}$ scissoring mode $\left(\delta \mathrm{CD}_{2}\right)$ of the alkyl chain of a deuterated $\mathrm{C}_{18}$ fatty acid and alcohol monolayers. Spectra on the left were collected at $24{ }^{\circ} \mathrm{C}$ and spectra on the right at $2{ }^{\circ} \mathrm{C}$.

Monolayers usually can pack in the three different lattice patterns: hexagonal $\left(\delta \mathrm{CH}_{2} 1468\right.$ $\left.\mathrm{cm}^{-1}, \delta \mathrm{CD}_{2} 1089 \mathrm{~cm}^{-1}\right)$, triclinic $\left(\delta \mathrm{CH}_{2} 1471 \mathrm{~cm}^{-1}, \delta \mathrm{CD}_{2} 1092 \mathrm{~cm}^{-1}\right)$ and orthorhombic $\left(\delta \mathrm{CH}_{2}\right.$ $1462 / 1474 \mathrm{~cm}^{-1}, \delta \mathrm{CD}_{2} 1084 / 1094 \mathrm{~cm}^{-1}$ doublet).$^{2-5}$ Due to differences in the interchain vibrational interactions of the surfactant molecules each lattice packing structure results in a unique scissoring mode frequently. At a frequency of $1089 \mathrm{~cm}^{-1}$, it is determined that the $\mathrm{C}_{18}$ fatty acid, fatty alcohol and 50:50 mixture comprising the monolayers are packed in hexagonal arrangements at both temperatures. Because of the single peaks at both temperatures, this also supports the idea that the films remain miscible, as splitting of the peak would likely occur with two different hexagonal phases. Changes in shoulder heights are almost certainly due to baselining procedures described in the experimental section, and not changes in the film. 


\section{Acid}
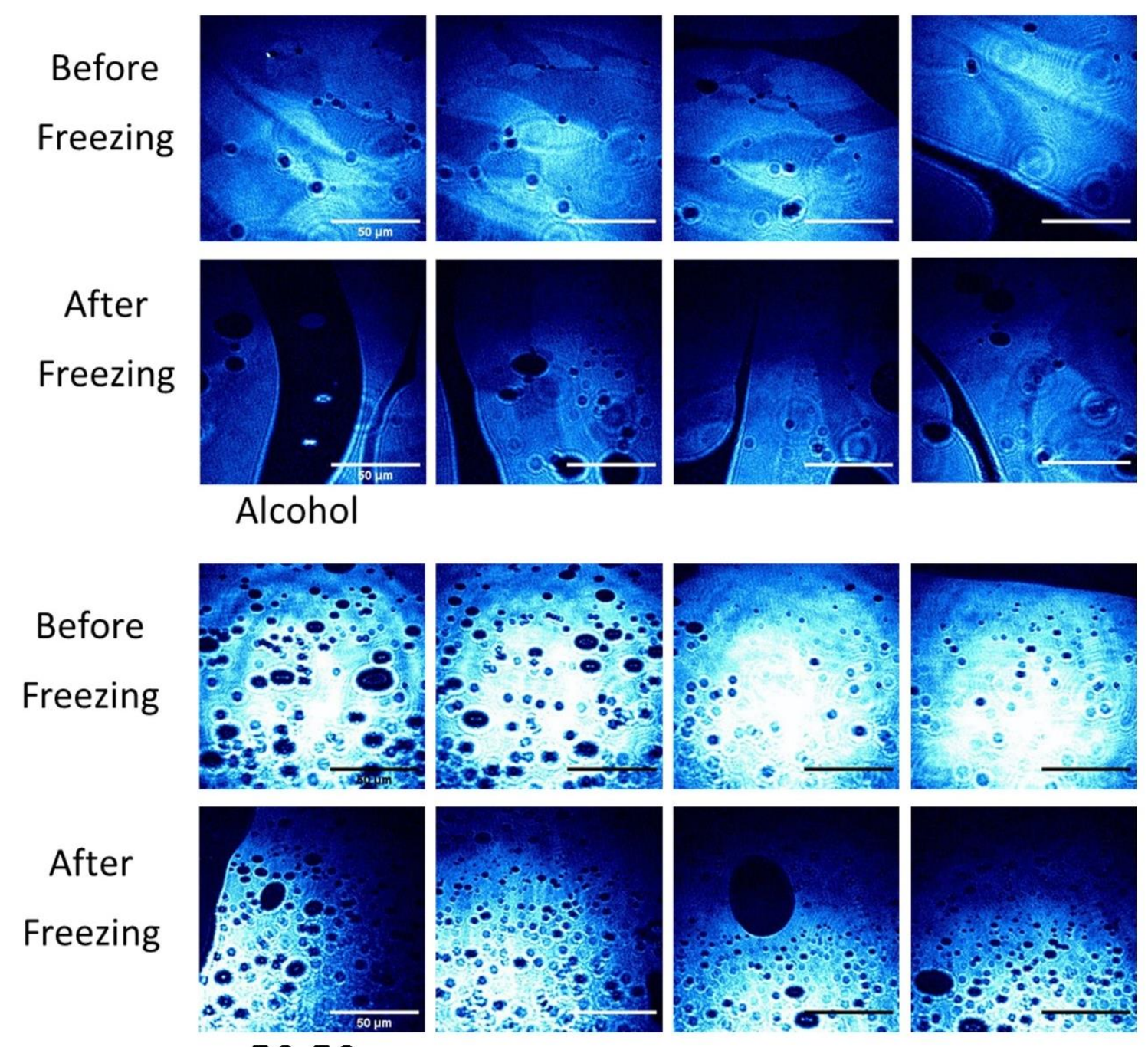

$50: 50$

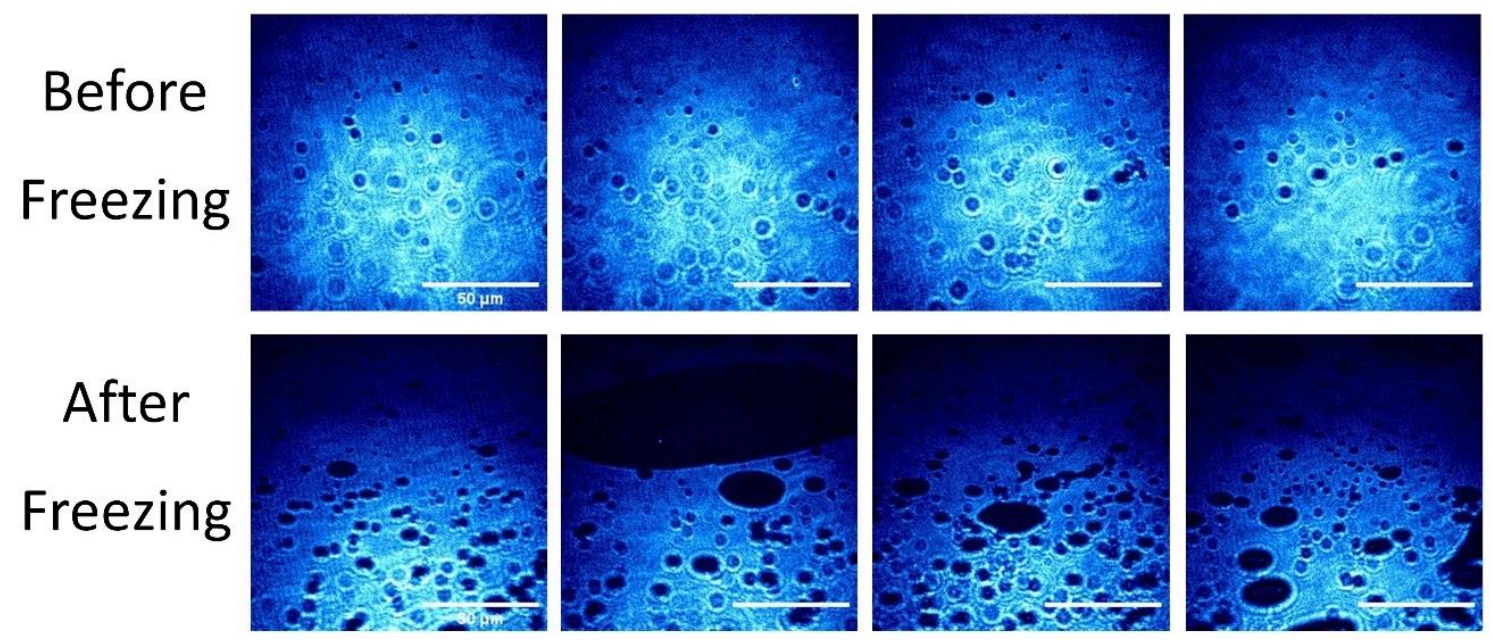

Figure S4: Additional bam images corresponding to the same conditions used for Figure 8. Scale bar is $50 \mu \mathrm{m}$ for each image. 
Table S1

\begin{tabular}{|c|c|c|c|}
\hline Compound & Phase & $\begin{array}{l}\text { Temperature } \\
\left({ }^{\circ} \mathbf{C}\right)\end{array}$ & \begin{tabular}{|l} 
MMA Range \\
$\left(\AA^{2} /\right.$ Molecule $)$
\end{tabular} \\
\hline Fatty Alcohol & $\mathrm{L}_{1}-\mathrm{L}_{2} / \mathrm{L}_{2}$ & 24 & $31.30-20.00$ \\
\hline Fatty Alcohol & $\mathrm{L}_{2} / \mathrm{L}_{2} \mathrm{\prime}$ & 24 & $20.00-18.00$ \\
\hline Fatty Alcohol & LS/S & 24 & $18.00-17.20$ \\
\hline Fatty Alcohol & Collapse & 24 & $17.20-16.60$ \\
\hline Fatty Acid & $\mathrm{L}_{1}-\mathrm{L}_{2} / \mathrm{L}_{2}$ & 24 & $31.65-24.18$ \\
\hline Fatty Acid & $\mathrm{L}_{2} / \mathrm{L}_{2}{ }^{\prime}$ & 24 & $24.18-19.57$ \\
\hline Fatty Acid & LS/S & 24 & $19.57-19.25$ \\
\hline Fatty Acid & \begin{tabular}{|l} 
Collapse \\
\end{tabular} & 24 & $19.25-19.18$ \\
\hline $50: 50$ & $\mathrm{~L}_{1}-\mathrm{L}_{2} / \mathrm{L}_{2}$ & 24 & $31.67-22.51$ \\
\hline $50: 50$ & $\mathrm{~L}_{2} / \mathrm{L}_{2}$, & 24 & $22.51-19.81$ \\
\hline $50: 50$ & LS/S & 24 & 19.81-18.66 \\
\hline $50: 50$ & Collapse & 24 & $18.66-18.56$ \\
\hline Fatty Alcohol & $\mathrm{L}_{1}-\mathrm{L}_{2} / \mathrm{L}_{2}$ & 16 & $31.30-19.50$ \\
\hline Fatty Alcohol & $\mathrm{L}_{2} / \mathrm{L}_{2}{ }^{\prime}$ & 16 & $19.50-17.96$ \\
\hline Fatty Alcohol & LS/S & 16 & $17.96-17.40$ \\
\hline Fatty Alcohol & Collapse & 16 & $17.40-17.37$ \\
\hline Fatty Acid & $\mathrm{L}_{1}-\mathrm{L}_{2} / \mathrm{L}_{2}{ }^{\prime}$ & 16 & $31.65-24.00$ \\
\hline Fatty Acid & $\mathrm{L}_{2} / \mathrm{L}_{2} \mathrm{\prime}$ & 16 & $24.00-19.30$ \\
\hline Fatty Acid & LS/S & 16 & $19.30-18.86$ \\
\hline Fatty Acid & Collapse & 16 & 18.86-19.79 \\
\hline $50: 50$ & $\mathrm{~L}_{1}-\mathrm{L}_{2} / \mathrm{L}_{2}$ & 16 & $31.68-22.51$ \\
\hline
\end{tabular}




\begin{tabular}{|c|c|c|c|}
\hline 50:50 & $\mathrm{L}_{2} / \mathrm{L}_{2}{ }^{\prime}$ & 16 & $22.51-19.54$ \\
\hline $50: 50$ & LS/S & 16 & $19.54-18.72$ \\
\hline $50: 50$ & \begin{tabular}{|l|} 
Collapse \\
\end{tabular} & 16 & $18.72-17.20$ \\
\hline Fatty Alcohol & $\mathrm{L}_{1}-\mathrm{L}_{2} / \mathrm{L}_{2}$ & 2 & $31.30-19.50$ \\
\hline Fatty Alcohol & $\mathrm{L}_{2} / \mathrm{L}_{2}{ }^{\prime}$ & 2 & $19.50-17.85$ \\
\hline Fatty Alcohol & LS/S & 2 & $17.85-16.70$ \\
\hline Fatty Alcohol & \begin{tabular}{|l|} 
Collapse \\
\end{tabular} & 2 & $16.70-16.60$ \\
\hline Fatty Acid & $\mathrm{L}_{1}-\mathrm{L}_{2} / \mathrm{L}_{2}$ & 2 & $31.65-23.50$ \\
\hline Fatty Acid & $\mathrm{L}_{2} / \mathrm{L}_{2}{ }^{\prime}$ & 2 & $23.5-18.80$ \\
\hline Fatty Acid & LS/S & 2 & $18.80-18.30$ \\
\hline Fatty Acid & Collapse & 2 & $18.30-18.27$ \\
\hline $50: 50$ & $\mathrm{~L}_{1}-\mathrm{L}_{2} / \mathrm{L}_{2}$ & 2 & $31.68-23.51$ \\
\hline $50: 50$ & $\mathrm{~L}_{2} / \mathrm{L}_{2}{ }^{\prime}$ & 2 & $23.51-20.65$ \\
\hline $50: 50$ & LS/S & 2 & $20.65-19.81$ \\
\hline $50: 50$ & \begin{tabular}{|l|} 
Collapse \\
\end{tabular} & 2 & $19.70-19.59$ \\
\hline
\end{tabular}




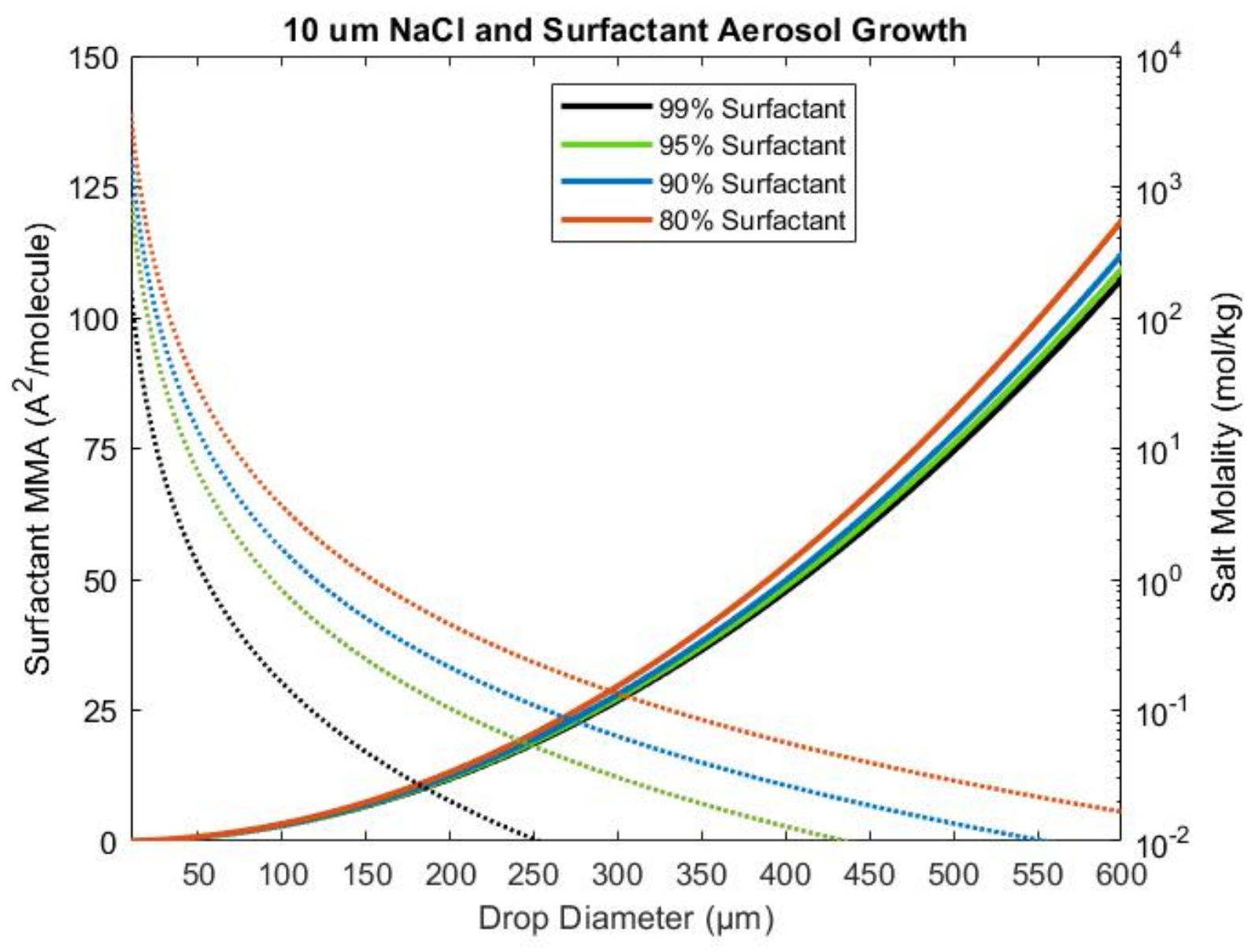

Figure S5: Changes to surfactant MMA (solid lines) and salt content (dashed lines) as a $10 \mu \mathrm{m}$ aerosol particle uptakes water and grows into a droplet. The initial dry aerosol is assumed to be composed of only surfactant and salt. Surfactant percentages shown in the legend are mass fractions. 


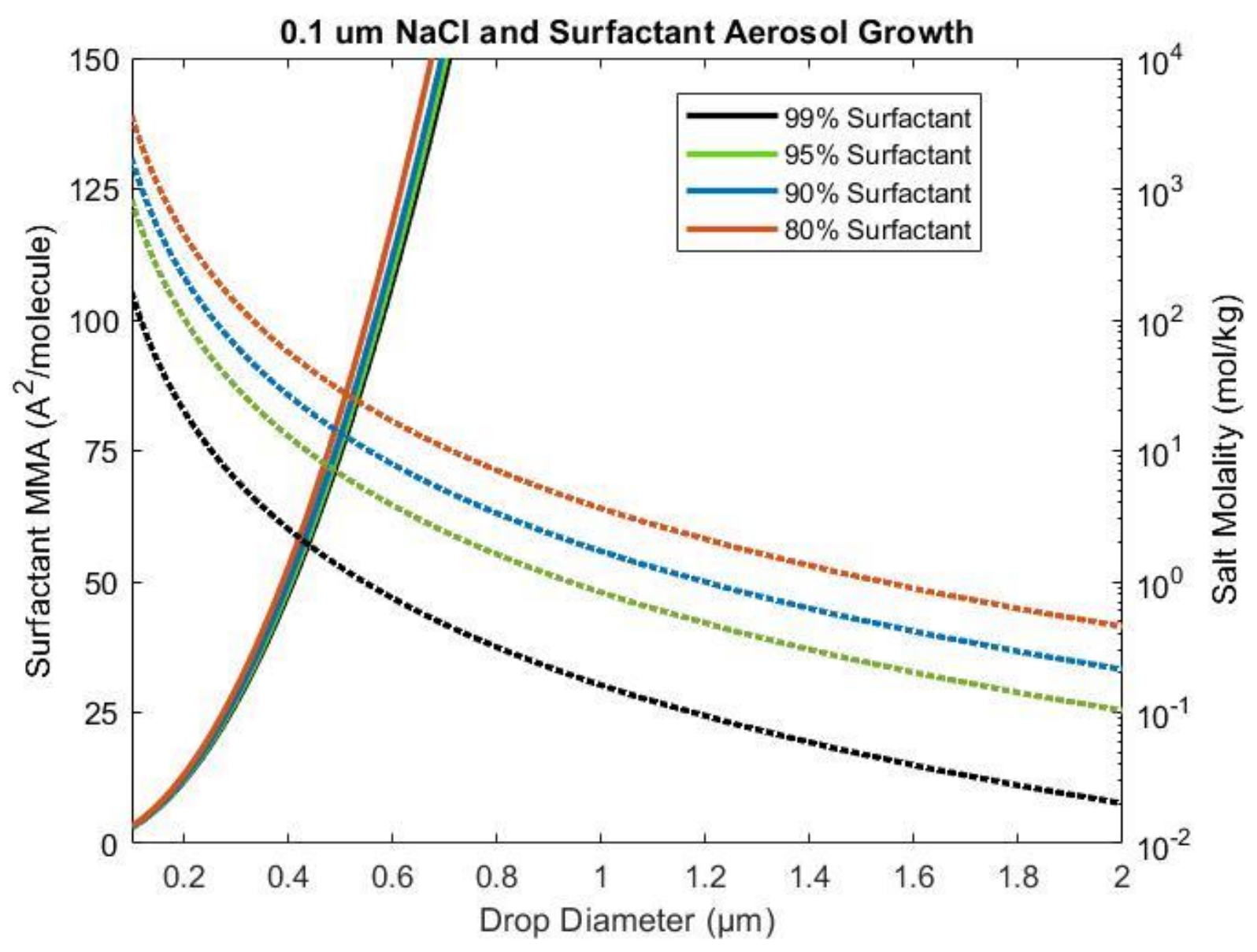

Figure S6: Changes to surfactant MMA (solid lines) and salt content (dashed lines) as a $0.1 \mu \mathrm{m}$ aerosol particle uptakes water and grows into a droplet. The initial dry aerosol is assumed to be composed of only surfactant and salt. Surfactant percentages shown in the legend are mass fractions. 


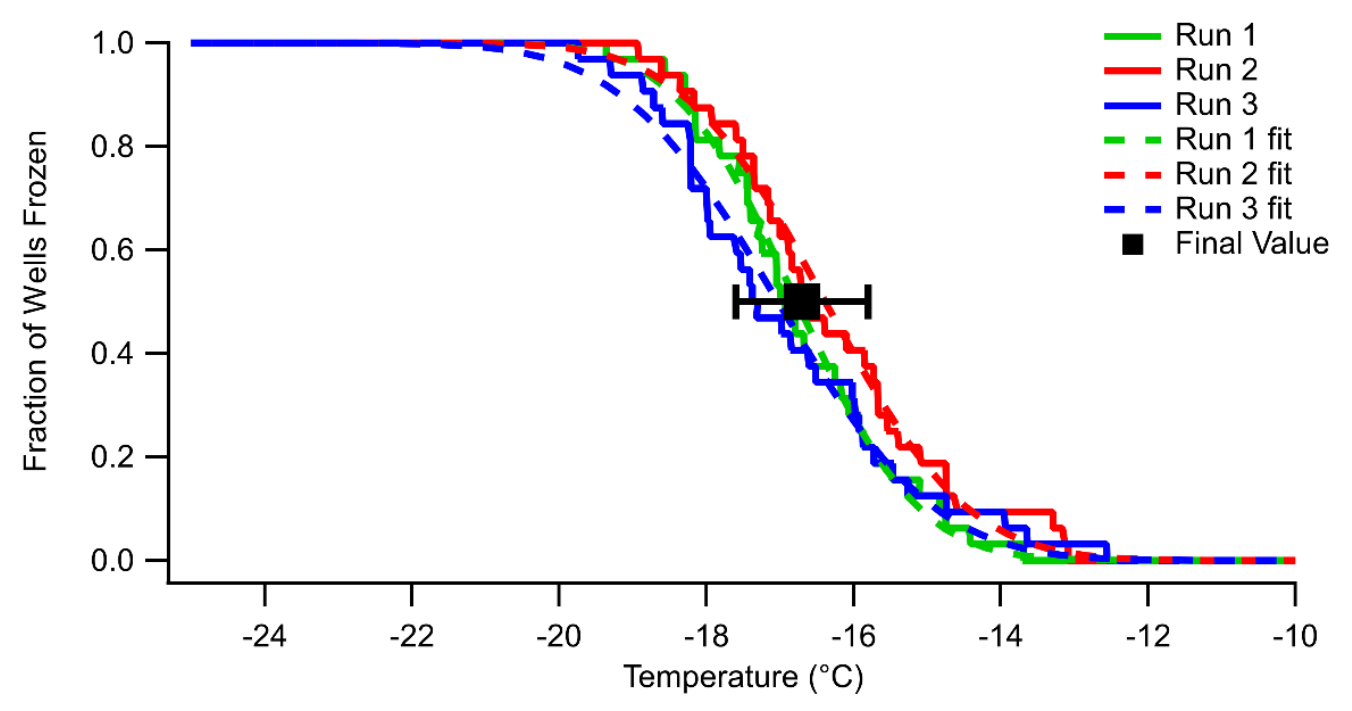

Figure S7: Example freezing curves of replicate experiments (solid lines) on $7 \AA^{2} /$ molecule deposited pure $\mathrm{C}_{18}$ fatty alcohol films. Each experiment consisted of 32 replicate samples that froze at different temperatures. Fits of this experimental data to cumulative gaussian distributions are shown as well (dashed lines). Runs 1 and 2 were performed with different surfactant stock solution from run 3. The black box indicates the final reported value for the temperature of $50 \%$ sample freezing, with error bar for the reported uncertainty. 
References:

(1) Cochran, R. E.; Laskina, O.; Jayarathne, T.; Laskin, A.; Laskin, J.; Lin, P.; Sultana, C.; Lee, C.; Moore, K. A.; Cappa, C. D.; Bertram, T. H.; Prather, K. A.; Grassian, V. H.; Stone, E. A. Analysis of Organic Anionic Surfactants in Fine and Coarse Fractions of Freshly Emitted Sea Spray Aerosol. Environ. Sci. Technol. 2016, 50 (5), 2477-2486. https://doi.org/10.1021/acs.est.5b04053.

(2) Small, D. M. Lateral Chain Packing in Lipids and Membranes. J. Lipid Res. 1984, 25 (13), 1490-1500.

(3) Mendelsohn, R.; Brauner, J. W.; Gericke, A. External Infrared Reflection Absorption Spectrometry of Monolayer Films at the Air-Water Interface. Annual Review of Physical Chemistry 1995, 46 (1), 305-334. https://doi.org/10.1146/annurev.pc.46.100195.001513.

(4) Adams, E. M.; Wellen, B. A.; Thiraux, R.; Reddy, S. K.; Vidalis, A. S.; Paesani, F.; Allen, H. C. Sodium-Carboxylate Contact Ion Pair Formation Induces Stabilization of Palmitic Acid Monolayers at High PH. Phys. Chem. Chem. Phys. 2017, 19 (16), 10481-10490. https://doi.org/10.1039/C7CP00167C.

(5) Rudd, B. A. W.; Vidalis, A. S.; Allen, H. C. Thermodynamic versus Non-Equilibrium Stability of Palmitic Acid Monolayers in Calcium-Enriched Sea Spray Aerosol Proxy Systems. Phys. Chem. Chem. Phys. 2018, 20 (24), 16320-16332. https://doi.org/10.1039/C8CP01188E. 